\title{
Notas sobre a Dinâmica dos Impulsos em Nietzsche
}

\author{
Bruno Martins Machado \\ Universidade Estadual de Campinas
}

\begin{abstract}
RESUMO
O presente artigo tem como propósito evidenciar o dinamismo dos impulsos de acordo com o perspectivismo nietzscheano. Enfatizamos, sobretudo, o modo como os impulsos são apresentados por Friedrich Nietzsche como peças estruturantes para a moral e para a vida. Para tanto, exploramos como a relação entre os impulsos se apóia sobre a doutrina da vontade de poder. Entendemos que há um ganho importante ao evidenciarmos essa leitura, pois ela fornece instrumentos críticos seja para análises da moral, seja para análises do próprio homem. Para empreender essa proposta, utilizamos textos do próprio Nietzsche, com ênfase em obras publicadas durante sua vida; contudo não perdemos de vista a importância dos fragmentos póstumos. Também fizemos uso de alguns comentadores quando suas posições se mostraram relevantes para a compreensão desses escritos.
\end{abstract}

Palavras-chave: Nietzsche; impulsos; vontade de poder; perspectivismo; moral.

\begin{abstract}
Remarks on Impulses' Dynamics in Nietzsche's Work

This paper intends to make evident the dynamism of the impulses according to Nietzsche's perspectivism. We emphasized, above all, the way impulses are presented by Friedrich Nietzsche as an important key for understanding morals and life. As such, we explored how the relationship among the impulses leans on the doctrine of will to power. We understand that this has an important feature: it supplies critical instruments for the analysis of morals and of man himself. To achieve this goal, we used Nietzsche's texts, with emphasis on works published during his lifetime; however, we also recognized the importance of Nietzsche's posthumous fragments. We also made use of some commentators' writings when their opinions were relevant for the comprehension of Nietzsche's.
\end{abstract}

Keywords: Nietzsche; impulses; will to power; perspectivism; morals.

\section{"O caminho que leva aos problemas fundamentais"}

Para abordar o tema psicologia em Nietzsche, dentre tantas possibilidades significativas, partiremos do importante aforismo 23 de Para Além de Bem e Mal . Nesse texto, de forma concisa, Nietzsche define e aponta o propósito de uma psicologia. O aforismo inicia da seguinte forma:

Toda psicologia, até o momento, tem estado presa a preconceitos e temores morais: não ousou descer às profundezas. Compreendê-la como morfologia e teoria da evolução da vontade de poder, tal como faço - isto é algo que ninguém tocou sequer em pensamento: na medida em que é permitido ver, no que foi até agora escrito, um sintoma do que foi até aqui silenciado. (Nietzsche, $1886 / 1992$, p. 29)

No trecho acima, o filósofo indica que a psicologia se manteve na superfície. Significa dizer que, presa a preconceitos, a psicologia permanece como uma ciência depositária do modo de conhecimento apresentado pela tradição científico-filosófica. O grande problema desse modo de produzir entendimento sobre o homem é que ele acaba promovendo um nivelamento entre as noções de homem, sujeito, "eu" e consciência. Então, a análise do homem através da psicologia se resume a fazer uma ciência dos atos da consciência, isto é, uma ciência do "eu". Portanto, temos um modelo que limita a compreensão que o homem pode ter de si mesmo.

Assim, o primeiro aspecto que Nietzsche propõe eliminar é a identificação da psicologia a uma ciência do "eu" (da consciência). A partir da derrocada do primado do sujeito emerge a importância das instâncias infraconscientes ${ }^{1}$. Seguindo essa perspectiva, a noção de um "eu" como núcleo substancial da alma se esfacela. Em seu lugar vem à tona o dinamismo do 
mundo dos impulsos. Nesse movimento em que a unidade formal que se estrutura em torno da noção de "eu" é posta de ponta-cabeça, a alma ressurge como símbolo da multiplicidade corpórea.

Com o esfacelamento da alma em uma multiplicidade de impulsos, a psicologia se volta para um mundo de eventos não-conscientes. Enquanto disciplina que analisa e interpreta a dinâmica dos nossos impulsos, afetos, pensamentos e pulsões, ela assume um papel importante diante das outras ciências. Se considerarmos que tais forças (impulsos, afetos, pensamentos e pulsões) são manifestações particulares da vontade de poder, então, podemos compreender o porquê da psicologia ser tomada como "morfologia e teoria da evolução da vontade de poder" (Nietzsche, 1886/ 1992, p. 29).

Morfologia assume a conotação de descrever modos de apresentação da vontade de poder. De forma alguma podemos pensar que a morfologia nietzscheana procura explicar as diferentes expressões da vontade de poder. Pela observação da morfologia das vontades percebemos o que opera em todas as forças: vontade de poder. Em um fragmento póstumo de 1888, Nietzsche explicita com mais detalhe o que ele quer dizer quando fala de uma morfologia. O próprio título do fragmento já nos remete diretamente à questão, ele se chama: "Vontade de poder. Morfologia". No texto, o filósofo nos apresenta modalizações da vontade de poder: "Vontade de poder como 'natureza'/ como vidal como sociedadel como vontade de verdadel como religião/ como arte/ como moral/ como humanidade." (Nietzsche, 1967d, p. 254).

Esse pequeno texto é muito útil para pensarmos como a vontade de poder assume diversas formas, de modo que seria um equívoco tomar uma dessas modalizações como essência da vontade de poder. Como Müller-Lauter atesta:

Ela [vontade de poder] não é um fundamento do mundo, que produz vida ou que se exterioriza como arte, ou se efetiva como humanidade. Muito ao contrário, as 'configurações' (Gestaltungen) apresentadas por Nietzsche são, segundo sua essência, vontade de poder. Tornar visível essa essência, nos 'âmbitos' de espécie diversa, é a tarefa de uma 'morfologia' da vontade de poder (Müller-Lauter, 1997, pp. 86-87).

Então, se a vontade de poder se configura como aspecto fundamental das modalizações das forças do nosso corpo, podemos afirmar que o mundo dos impulsos, afetos, sentimentos é regido pela hierarquia do comando. Para tentar exercer o comando as instâncias infraconscientes buscam estratégias de domínio. Sob tal perspectiva, "a elaboração da teoria da vontade de poder faz, então, dos instintos e dos afetos as instâncias privilegiadas, primeiras, a partir das quais se deve necessariamente construir a experiência de pensar para Nietzsche." (Wotling, 1998, p. 19) Ao condicionar o pensamento à luta inconsciente das forças, o filosofo se inscreve em uma nova tendência investigativa que buscava evidenciar a importância do dinamismo infraconsciente na determinação de comportamentos do homem. Assim, eleger a psicologia como uma morfologia da vontade de poder significa para Nietzsche reafirmar seu perspectivismo, pois uma teoria dos impulsos desvela a possibilidade de abertura para novas configurações. Ela se mostra como um instrumento de análise do homem e do modo como ele constrói sua cultura.

O fato principal é que a psicologia nos leva através da pergunta pela constituição e dinâmica dos processos infraconscientes a questões próprias ao homem, ou seja, própria à constituição de uma moral. Vale ressaltar aqui um ponto que veremos logo mais à diante: que moral é constituída a partir das avaliações das instâncias infraconscientes. Nesse sentido, também a moral tem como parâmetro o desenvolvimento e as modalizações da vontade de poder. Isso nos leva à conclusão de que a moral deve ser compreendida como objeto da psicologia.

Ao destacar o âmbito dos impulsos, Nietzsche abriu caminho para entendermos a amplitude interpretativa de sua filosofia, que assume um alcance bastante amplo quando compreendida a partir do dinamismo psicológico. De fato, tal proposta significa ousar uma nova perspectiva na qual "a psicologia seja novamente reconhecida como rainha das ciências, para cujo serviço e preparação existem as demais ciências. Pois a psicologia é, uma vez mais, o caminho para os problemas fundamentais" (Nietzsche, 1886/ 1992, p. 30).

\section{Moral enquanto "linguagem simbólica dos afetos"}

Nosso segundo passo tem início com a pergunta: O que é a moral segundo o perspectivismo nietzscheano? Em razão das diferentes maneiras como Nietzsche aborda esse tema, chegar a uma única resposta não é uma tarefa simples. Como nosso percurso se orienta rumo a uma discussão acerca dos impulsos, partiremos da compreensão do que é a moral quando observada sob a óptica dos impulsos. Apresentaremos neste tópico uma perspectiva na qual a moral emerge como 
um conjunto de forças que estabelecem um modo específico de interação com o mundo e que tentam expandir tal modo de interação consolidando-a como exercício obrigatório para toda e qualquer força.

Nos seus textos, Nietzsche evidencia que a moral foi erguida sobre uma dupla construção: (i) Ela é uma imposição tirânica de uma determinada perspectiva, concebida a partir da sujeição de um grupo de forças a outras. Podemos encontrar tal caracterização no aforismo 188 de Para Além de Bem e Mal no qual o filósofo defende que "toda moral é, em contraposição ao laisser aller ['deixar ir'], um pouco de tirania contra a 'natureza', e também contra a 'razão" (Nietzsche, 1886/1992, p. 87). (ii) Ela opera no âmbito inconsciente, isto é, toda a luta pela imposição de perspectivas independe da "razão". Razão entendida aqui como sinônimo de consciência (Nietzsche, 1887/2001, p. 249).

Devemos ter em vista que, enquanto imposição tirânica, a moral se exerce como "uma demorada coerção" (Nietzsche, 1886/1992, p. 87), ou seja, ela funciona como um processo de coação, no qual as forças que estão no domínio impõem sua própria tendência. Verificamos que as forças estão sempre impondo seu modo de funcionamento e sempre querendo expandir seu comando mais e mais. Assim, aquelas que comandam ditam um modo específico de vida, sendo responsáveis por estabelecerem valores na arte, na música, no pensar etc.

Aquilo que podemos extrair dessa dinâmica apresentada por Nietzsche é: o corpo é uma configuração específica de forças. Os impulsos, os afetos ou os instintos, quando seguem a mesma tendência das forças que nos coagem são caracterizados como moralmente aceitos. Por outro lado, aqueles impulsos que vão de encontro à hierarquia estabelecida são tomados como moralmente não-aceitos. Estes são obrigados, de algum modo, a se encaixarem diante das exigências morais ou a criarem uma nova moral. Assim, quando por muito tempo uma configuração de impulsos se afirma como predominante, um modo específico de viver é cristalizado e acabamos por acreditar que um certo padrão de comportamentos é "natural". Porém, querer manter um modo permanente para o exercício dos impulsos significa tolher o surgimento de qualquer outra força diferente daquelas que estão no comando.

Se seguirmos a perspectiva nietzscheana e tomarmos "o corpo como fio condutor" (Nietzsche, 1967c, p. 106), podemos nos perguntar: qual a relação de tais impulsos com o nosso modo de existir? Chegamos a um ponto seminal, não apenas para a construção do texto, mas também para o entendimento do modo como Nietzsche estrutura a relação dos impulsos com o mundo. O filósofo atesta que nada pode ser " "dado" como real, exceto nosso mundo de desejos e paixões" (Nietzsche, 1886/1992, p. 42). Ele acrescenta que não podemos "descer ou subir a nenhuma outra 'realidade', exceto à realidade de nossos impulsos [unsrer Triebe]..." (Nietzsche, 1886/1992, p. 42) Portanto, a ordem de realidade na qual se inscreve a moral é aquela forjada pela dinâmica de nossos impulsos.

Damos então o nosso primeiro passo ao apresentarmos uma resposta à pergunta o que é a moral. Isto porque se entendermos que a existência afirma-se a partir de um dinamismo de forças, então a moral emerge como um indicativo da perspectiva de comando que prevalece em um determinado corpo, ou seja, ela pode ser interpretada como um sintoma de um determinado arranjo de impulsos. Enquanto sintoma a moral revela juízos de valores, quer dizer, ela demonstra uma forma de valorar, mais especificamente, ela denota uma hierarquização de forças. Nesse sentido, uma moral nunca pode ser tomada como "a verdadeira", pois enquanto juízos de valor, as hierarquias de impulsos "têm valor apenas como sintomas, são considerados apenas como sintomas - em si, tais juízos são bobagens." (Nietzsche, 1888/2006, p. 18) Assim, aos olhos de um psicólogo atento, que sabe que temos acesso apenas aos sintomas, "as morais não passam de uma linguagem simbólica dos afetos [eine Zeichensprache der Affekte]" (Nietzsche, 1886/1992, p. 87).

\section{Os impulsos, vida e vontade de poder}

Não apenas a moral, mas também, o corpo e a própria realidade podem ser descritos a partir do âmbito dos impulsos. Podemos constatar que o pensamento nietzscheano se aglutina em torno da vida, pois ela é o campo fundamental onde se efetiva a dinâmica dos impulsos. Assim, seguimos a mesma trilha sobre a qual moral, corpo, realidade e vida se estruturam, qual seja, o percurso cujo fundamento são os impulsos. Nesses termos, tal delineamento leva à afirmação: "A vida mesma é essencialmente apropriação, ofensa, sujeição do que é estranho e mais fraco, opressão, dureza, imposição de formas próprias, incorporação e, no mínimo, e mais comedido, exploração" (Nietzsche, $1886 / 1992$, p. 171). Perceber a vida como um complexo de forças significa afirmar um modo de análise e de interpretação do mundo, pois toda aquela dinâmica de impulsos sobre a qual construímos nossa compreensão do que é a moral também é aplicável ao vivente. Cada impulso quer impor sua perspectiva, cada impulso 
quer se colocar no comando. Assim, o mundo se configura para nós como um conjunto de interpretações processadas de acordo com nossa hierarquia de impulsos. Julgando, interpretando e valorando - estamos sempre elaborando "realidades" a partir de nossos impulsos. Desse modo construímos nossas vidas, nosso mundo, nossa moral. Como afirma o próprio Nietzsche: "Não existem fenômenos morais, apenas uma interpretação moral dos fenômenos..." (Nietzsche, 1886/ 1992, p. 73). Nesse sentido, qualquer evento, a partir do momento em que entramos contato com ele, já se torna um fato moral. Assim, grande parte do empreendimento filosófico de Nietzsche consiste em aguçar nossos sentidos para que entendamos o mundo como um imenso conjunto de valores e que, frente a esta gigantesca construção, possamos nos perguntar pelo valor dos valores. É a hora de aprender a colocar questões.

Sendo o mundo interpretação, então não há uma verdade em si: existem apenas ilusões erguidas sobre valores. Tal proposta nos leva a concluir que, a todo momento, estamos nos relacionando com diversas possibilidades de leitura e compreensão dos eventos. Importante é perceber que Nietzsche não diferencia o mundo e as suas interpretações, para o filósofo, só há interpretações. Somente assim, ou seja, mostrando como viver tem sua conotação estruturada sobre a ordem dos impulsos, é possível para Nietzsche olhar para a vida como uma força e atestar: "vida é vontade de poder" (Nietzsche, 1886/1992, p. 20). A vontade de poder se apresenta como a "única qualidade que se deixa encontrar" (Müller-Lauter, 1997, p. 83).

Contudo, não podemos conceber a vontade de poder como um dado efetivo para onde se direcionam os impulsos. A efetividade da vontade de poder se dá na unidade da organização e combinação de quanta de poder. Percebemos isso quando observamos que na dinâmica das forças,

a qualidade não existe como algo subsistente por si, não como sujeito ou como quase-sujeito (...) a única qualidade já é sempre dada em tais quantitativas particularizações, senão ela não poderia ser essa qualidade. Toda vontade de poder é, com efeito, dependente de sua oposição a outras vontades de poder, para poder ser vontade de poder. A qualidade de 'vontade de poder' não é um Um efetivo; esse um nem subsiste de alguma maneira para si, nem sequer é 'fundamento do ser' (Seinsgrund). Só há 'efetiva' unidade como organização e combinação de quanta de poder. (Müller-Lauter, 1997, pp. 84-85)

Em um aforismo póstumo, Nietzsche é mais direto ao correlacionar nossos impulsos com um modo de viver (em outros termos, com o modo de produzir valores) e ambos com a vontade de poder. O filósofo atesta:

Nossa inteligência, nossa vontade, assim como, nossas sensações dependem de nossos julgamentos de valor: Esses aqui respondem aos nossos impulsos [unseren Trieben] e à suas condições de existência. Nossos impulsos [Unsere Triebe] são redutíveis à vontade de poder. A vontade de poder é o último facto, para o termo último que nossos impulsos alcançam. (Nietzsche, 1967b, p. 661)

Tratar com a vida, portanto, significa determinar o modo como os impulsos impõem seu funcionamento uns aos outros. A relação entre comandar e obedecer traz consigo, concomitantemente, a sensação do comando, ou seja, o sentimento de poder.

Mas o que significa este "sentimento de poder"? Ele é constituído a partir da sensação do comando oriunda dos embates entre os impulsos. Quando um impulso subjuga outro, impondo seu modo de organizar as experiências, isso é traduzido como uma ampliação da sensação de poder. Na luta entre os impulsos, o aumento de potência ou a superação de resistência produz prazer e a despotencialização ou o bloqueio do crescimento produz desprazer. Com o propósito de perpetuar as sensações de prazer, o corpo apóia uma tendência específica de forças. O objetivo é: não contradizer uma constituição dominante e, principalmente, uma organização hierárquica de impulsos que está no comando. Essa tendência constitutiva de todo impulso - que busca impor seu funcionamento a outros ampliando ainda mais sua rede de comando e com isso sua sensação de poder - foi chamada por Nietzsche de superação (Überwindung). A superação acontece porque uma força não se anula, ela busca sempre mais e para conseguir seu propósito, ela tende a superar outras. Não só outras forças, mas também superar a si mesma. Nietzsche nos apresenta a aproximação entre vontade de poder e superação em Assim Falou Zaratustra, no discurso "Das Mil Metas e da 'Única' Meta", quando o profeta do Eterno Retorno atesta: "Uma tábua de valores está suspensa sobre cada povo. Vê, é a tábua de suas superações; Vê, é a voz da sua vontade de poder" (Nietzsche, 1885/1999, p. 99).

Esse é, também, o primeiro anúncio da vontade de poder tal como Nietzsche a pensou nas suas obras de maturidade. No trecho acima, falando sobre os diversos códigos morais de cada povo, o filósofo chama nossa atenção para a efetivação da vontade de poder via superação. Ele indica que diante de qualquer perspec- 
tiva moral uma tendência permanece, a saber, a luta pela superação, a busca por acréscimo de sentimento de poder.

\section{A vida como um dinamismo para o comando}

Percebemos, então, a tentativa de Nietzsche em buscar explicar os comportamentos do homem a partir da doutrina da vontade de poder. Assim, a vontade de poder se consolida como o instrumento elementar para o modo como os impulsos interagem uns com os outros. Segundo Paul van Tongeren, "Vontade de poder é o nome dado à perspectiva com a qual todas as coisas são pensadas e interpretadas como um processo de interpretação que constantemente se esforça em superar outras interpretações anteriores" (Tongeren, 2004, p. 162).

Nesse sentido, qualquer impulso, instinto ou afeto tem como tendência inexorável a busca pela superação, ou seja, deseja ir além, quer superar a si mesmo. Portanto, desde nossos impulsos mais elementares às mais altas elaborações intelectuais, tudo é redutível à vontade de poder. Sob essa conotação, podemos ler as realizações científicas, culturais, políticas, filosóficas e artísticas. Uma importante leitura da relação da vontade de poder com os nossos impulsos nos é apresentada por Wotling:

A teoria nietzscheana dos afetos e dos instintos nada mais é do que uma linguagem que permite descrever a aplicação da hipótese da vontade de poder a um problema específico: a análise do homem e da constituição da cultura. Ela tem como propósito mostrar como se efetua no campo humano a atividade fundamental da interpretação. (Wotling, 1995, p. 92)

Sob tal conotação, podemos apreender o estatuto da psicologia nietzscheana como um processo interpretativo no qual os instintos, os afetos, os impulsos não possuem uma determinação última que lhes garanta a existência em si mesma. Tudo é relação de forças, isto é, luta entre impulsos. Logo, tudo está sob a égide da vontade de poder.

Para especificar com mais clareza a superação, voltemos nossa atenção rapidamente à noção de poder. O poder também não possui uma identidade ou uma substancialidade, ele só se efetiva nas relações das forças. No caso do homem, na relação entre seus impulsos. Como cada relação é própria e específica, o poder assume os contornos das forças que estão em combate no momento. Porém, o único direcionamento que perdura é a busca pelo comando, pelo domínio o que marca um constante direcionamento para superar uma determinada hierarquia de impulsos. Nesse percurso, não há um caminho determinado, cada configuração hierárquica de vontades de poder ${ }^{2}$ delineia um arranjo específico de impulsos e, portanto, um tipo de direcionamento para nosso comportamento. Essa luta gera todo dinamismo da vida.

\section{A "espiritualização": uma estratégia dos impulsos}

Vimos até agora que a vida se efetiva através da luta entre os impulsos e que a descarga de um impulso pode levar a um sentimento de poder que, por sua vez, é traduzido como prazer ou desprazer, dependendo da configuração de forças que predominam em um corpo. É evidente que todo corpo tende a fugir do desprazer, por isso, há diversos modos de se trabalhar com um impulso. Isso nos leva a voltarmos nossa atenção em alguns modos como o corpo opera a descarga dos impulsos. Para Nietzsche, um impulso não pode ser visto sem sua efetivação, isto é, um impulso já é a manifestação de uma determinada configuração hierárquica de forças dominantes e dominadas. Portanto, um impulso é um exercício efetivo do corpo no mundo. Nesse processo, o que se torna evidente é o exercício de comando, uma tarefa que é estabelecida através da coerção. As forças de um corpo são coagidas a se dobrarem perante uma determinada perspectiva. Desde Humano Demasiado Humano (publicado em 1878), Nietzsche já pensava em como poderia acontecer o exercício dos impulsos e toda dinâmica psicológica na qual um corpo poderia ser inscrito. Porém, é em Aurora (publicado em 1881) que ele se aprofunda no tema. Pretendemos ressaltar aqui que: mesmo antes de traçar a elaboração mais madura de seu conceito de vontade de poder, Nietzsche já trabalhava com uma leitura do mundo que via na interpretação e na superação os traços mais característicos do dinamismo psicológico. É nesse sentido que, no aforismo 109 de Aurora, Nietzsche atesta que para se rechaçar um impulso é possível proceder das seis maneiras abaixo:

(i) Evitar as ocasiões para satisfazer o impulso e, através de longos, cada vez mais longos períodos de não satisfação, enfraquecê-lo e fazê-lo secar.

(ii) Fixar uma estrita regularidade na sua satisfação; ao impor-lhe dessa forma uma regra e colocar seu fluxo e refluxo em firmes limites de tempo, ganha-se intervalos em que ele não mais incomoda.

(iii) Entregar-se deliberadamente à satisfação selvagem e irrefreada de um impulso, para vir a ter nojo dele e, com este nojo, adquirir poder sobre o impulso. 
(iv) [Através de um artifício intelectual], ligar firmemente à satisfação um pensamento muito doloroso, de modo que, após algum exercício, o próprio pensamento da satisfação é sentido como doloroso.

(v) [Promover o] deslocamento de suas quantidades de energia, ao impor-se um trabalho particularmente duro e cansativo ou sujeitar-se deliberadamente a um novo estímulo e prazer, guiando assim para outros canais os pensamentos e o jogo das forças físicas.

(vi) Enfraquecer e oprimir toda sua organização física e psíquica, alcança naturalmente o objetivo de enfraquecer um determinado impulso veemente: como faz, por exemplo, quem priva de alimento sua sensualidade, e com isso também faz definhar e arruína seu vigor e, não raro, seu entendimento, à maneira do asceta. (Nietzsche, 1881/2004, pp. 79-80)

Observamos então que Nietzsche buscava demonstrar que um impulso pode ter seu exercício efetivado de diferentes modos. Para nosso interesse aqui, vale ressaltar que todo esse processo de refinamento dos modos de descarga energética Nietzsche chamou mais tarde (no seu período de maturidade) de espiritualização (Vergeistigung). Como explica Wotling:

A espiritualização não é a negação do instinto, mas seu refinamento, sua expressão de acordo com uma forma mais atenuada. A busca pela espiritualização não consiste em sufocar a violência de um instinto ou de um afeto, mas em moderar seu poder deslocando seu ponto de atuação. (Wotling, 1998, p. 30)

\section{Da "espiritualização" à sublimação}

Walter Kaufmann (1970) captou com propriedade o processo de espiritualização, sobretudo, quando caracterizou de maneira bastante elaborada a noção de sublimação. No processo de sublimação descrito por Nietzsche, o intelecto é utilizado como ferramenta para promover a chegada de um impulso ao seu objetivo, re-estabelecendo o balanço de energia do corpo $\mathrm{e}$, por conseguinte, um funcionamento saudável.

Sublimação é um termo já usado desde a "Alemanha medieval como uma adaptação do latim sublimare; e, nos tempos modernos, Goethe, Novalis e Schopenhauer o empregaram. Não obstante, foi Nietzsche quem primeiro lhe atribuiu a conotação que possui hoje" (Kaufmann, 1970, p. 189). O termo latino sublimare remete de início ao sentido utilizado na química, quando um corpo passa direto do estado sólido para o gasoso ou vice-versa.

Em Humano Demasiado Humano, no primeiro aforismo, Nietzsche (1878/2000) fala de sublimação mas utiliza o termo com uma conotação ainda muito próxima da química. Somente no segundo volume de Humano Demasiado Humano, no aforismo 95, Nietzsche faz uso da expressão "sexualidade sublimada" com uma conotação semelhante a que observamos atualmente. Como indicou Kaufmann (1970), as bases da sublimação foram traçadas a partir de seis maneiras diferentes de se lidar com os impulsos. Dentre tais modos, apresentados em linhas anteriores, é a quinta forma de descarga energética que caracteriza a sublimação. Quer dizer que, para Nietzsche, alguns impulsos, em vez de serem descarregados nos seus alvos mais comuns, são direcionados a outras atividades.

Contudo, é valido destacar que sublimar não significa trocar um impulso por outro indiscriminadamente. Mesmo sendo uma operação que se passa em um âmbito não consciente, a sublimação exige um certo domínio sobre si. Para evitar descargas que se confrontem diretamente com a tendência hierárquica preponderante, o que ocasionaria como vimos sensações de desprazer. Na sublimação, o corpo canaliza a energia e o objetivo de um impulso para serem descarregados de forma mais elaborada, não tão direta e impactante. Afirmar que a sublimação não passa de uma confusão imposta aos impulsos, ou ainda, atestar que sublimar seria uma simples substituição de um objeto por outro, de uma ação por outra, isto seria um equívoco. Tais alegações não se sustentariam porque, segundo a proposta nietzscheana, sublimar um impulso não consiste em manter sua energia e trocar apenas seu objeto. Isto porque, como vimos, a qualidade essencial de um impulso só se sustenta enquanto vontade de poder. O que interessa no exercício de um impulso é manter toda configuração hierárquica de forças que se formou. Ao ser efetivado, há como vimos uma sensação de prazer ocasionada pela superação de um obstáculo. Nesse sentido, o objeto do impulso nos revela a qualidade que só pode ser entendida a partir dos quanta de forças presentes em uma determinada hierarquia. Um impulso é quantum de poder, são forças em exercício configurando uma determinada hierarquia. Portanto, o impulso, na medida em que revela uma hierarquia, não pode ser trocado e, caso o fosse, estaríamos tratando com uma outra organização de forças diferentes.

Nietzsche "insiste - em conformidade com a tradição - que o que permanece é a essência e o que muda é o acidente" (Kaufmann, 1970, p. 191). Ele pode afirmar isso porque toda força é efetivação da vontade de poder. Assim, todo fim, todo objetivo, é um mero acidente da vontade de poder, o que interessa é exercer o comando. Então, segundo Nietzsche, não apenas a tendência se conserva, mas também o objeto do 
impulso (comandar e o prazer do comando). Em última instância, como vimos anteriormente, segue a mesma regra: a tendência do impulso é ampliar sua sensação de poder, através do comando.

É imprescindível observar que Nietzsche não depende estritamente dos termos espiritualização ou sublimação para desenvolver seu modelo psicológico sobre o funcionamento dos impulsos. Para além dos dois termos, o filósofo guarda o que seria mais importante: demonstrar o modo como o corpo trabalha com o dinamismo dos impulsos. Assim, mesmo se não designássemos esses processos por nenhum outro termo, estaríamos nos concentrando neles para efetuarmos uma leitura mais profunda da dinâmica da psicologia nietzscheana.

\section{Os impulsos como tradução da marca do homem: a indeterminação}

Expor a diferença entre a negação de um impulso e uma forma elaborada de descarregá-lo é um dos mais importantes aspectos trazidos pela noção de sublimação. A sublimação como qualquer outra forma de espiritualização tem como propósito melhorar a "natureza" (physis) do homem. Em outras palavras, a descarga dos impulsos traz uma sensação de bem-estar para a vida do homem. No sentido nietzscheano, physis ${ }^{3}$ indica todo o complexo que se concentra em torno desta multiplicidade de forças denominada corpo. Logo, "saber" trabalhar com os impulsos para que eles não sejam continuamente reprimidos revela uma forma de saber se relacionar com o mundo e consigo mesmo. Assim, durante a vida inúmeras possibilidades se abrem ao homem: forte-fraco, doente-saudável etc. Perspectivas que por estarem submetidas à organização dos impulsos lutam entre si para impor uma maneira própria de existir. Nesse sentido, a concepção de natureza defendida nos textos nietzscheanos configura-se enquanto marca da capacidade de encontrar novas possibilidades. Ocorrendo uma cristalização de forças em torno de uma única forma de valorar a vida, o corpo se torna algo "antinatural".

A crítica de Nietzsche à moral se efetiva segundo tais parâmetros, ou seja, quando a moral coage o homem a acreditar unicamente em "um único modo de vida", ela é uma moral inferior. Ela não torna o homem aberto a olhar para si e trabalhar com a multiplicidade dos seus impulsos. Então, "antinatural" seria atribuir à vida apenas uma forma especifica de interpretação, prender-se a uma única perspectiva. Em suma, seria virar as costas para a dinâmica dos impulsos. Em virtude dessa leitura, Nietzsche necessariamente precisa mostrar que o dinamismo dos impulsos deve acontecer para abrir a possibilidade para uma vida rica de interpretações.

A noção de "natureza humana", tal como nos apresenta a tradição filosófica desde a Modernidade, remete à imagem do homem como um animal distinto dos outros, que se diferencia por ser dotado de "consciência”. Porém, para Nietzsche, o homem é um animal que assim como os outros age segundo seus impulsos. Em última análise, sua vida independe da existência da consciência, sua vida é como vimos o retrato da dinâmica dos seus impulsos. O campo indefinido dos impulsos configura o único elemento que diferencia o homem de outras espécies de animais. Tal diferenciação não o coloca em uma posição mais ou menos privilegiada, ela apenas o qualifica como uma espécie diferente. Para o filósofo alemão, a marca exclusiva do homem seria seu estado indeterminado: "O homem ainda se modifica - está em transformação [ist im Werden].” (Nietzsche, 1967a, p. 458).

Destarte, o que caracteriza o animal homem é a possibilidade conseguir manter em constante movimento sua dinâmica de impulsos. Nesse sentido, a moral se opõe ao dinamismo porque ela coage o corpo a se identificar a uma configuração hierárquica específica. Mas, por outro lado, a moral é necessária para a sobrevivência do homem. Sendo um problema necessário, o homem tem como tarefa reelaborar nos termos da luta entre os impulsos a relação entre a natureza e a moral. O homem não é apenas um produto da natureza, mas uma forma da natureza de também criar para si, um constante experimento. "No homem estão unidos criador e criatura: no homem há matéria, fragmento, abundância, lodo, argila, absurdo, caos; mas no homem há também criador, escultor, dureza de martelo, deus-espectador e sétimo dia." (Nietzsche, 1886/1992, pp. 131-132).

Somente nessa acepção, o homem se eleva como caminho para possibilidades. Sua tarefa é, portanto, afirmar sua natureza mesmo diante da moral. Ele deve tornar-se o que ele é. Tal modo de vida só vai ser atingido quando soubermos reconhecer e trabalhar melhor nossos impulsos. É nesse sentido que emerge a contribuição da proposta nietzscheana de psicologia.

\section{REFERÊNCIAS}

Kaufmann, W. (1970). Nietzsche: Philosopher, psychologist, antichrist. New York: Meridian Books.

Müller-Lauter, W. (1997). A doutrina da vontade de poder em Nietzsche (O. Giacóia Jr., Trad.). São Paulo: Annablume.

Nietzsche, F. (1992). Para além de bem e mal (P. C. de Sousa, Trad.). São Paulo: Companhia das Letras. (Original publicado em 1886) 
Nietzsche, F. (1999). Assi habló Zaratustra (A. S. Pascual, Trad.). Madrid: Alianza Editorial. (Original publicado em 1885)

Nietzsche, F. (1999). Jenseits von Gut und Bose. Berlin/New York: Walter de Gruyter. (Original publicado em 1886)

Nietzsche, F. (1967a). Nachgelassene Fragmente 1880-1882. Em G. Colli \& M. Montinari (Orgs.), Kritische Studienausgegeben - KSA: Vol. 09. Berlin/New York: Walter de Gruyter.

Nietzsche, F. (1967b). Nachgelassene Fragmente 1884-1885. Em G. Colli \& M. Montinari (Orgs.), Kritische Studienausgegeben - KSA: Vol. 11. Berlin/New York: Walter de Gruyter.

Nietzsche, F. (1967c). Nachgelassene Fragmente 1885-1887. Em G. Colli \& M. Montinari (Orgs.), Kritische Studienausgegeben - KSA: Vol. 12. Berlin/New York: Walter de Gruyter.

Nietzsche, F. (1967d). Nachgelassene Fragmente 1887-1889. Em G. Colli \& M. Montinari (Orgs.), Kritische Studienausgegeben - KSA: Vol. 13. Berlin/New York: Walter de Gruyter.

Nietzsche, F. (2000). Humano demasiado humano (P. C. de Sousa, Trad.). São Paulo: Companhia das Letras. (Original publicado em 1878)
Nietzsche, F. (2001). A gaia ciência (P. C. de Sousa, Trad.). São Paulo: Companhia das Letras. (Original publicado em 1882/87)

Nietzsche, F. (2004). Aurora (P. C. de Sousa, Trad.). São Paulo: Companhia das Letras. (Original publicado em 1881)

Nietzsche, F. (2006). Crepúsculo dos ídolos (P. C. de Sousa, Trad.). São Paulo: Companhia das Letras. (Original publicado em 1888)

Tongeren, P. (2004). Reinterpreting modern culture. West Lafayette: Purdue University Press.

Wotling, P. (1995). Nietzsche et le probleme de la civilisation. Paris: PUF.

Wotling, P. (1998). Der weg zu den grundproblemen. NietzscheStudien, 26, 128-165.

Recebido: $13 / 06 / 2009$

Última revisão: 02/02/2010

Aceite final: 10/02/2010

Notas:

1 Ressaltamos que deliberadamente optamos por não partir de uma diferenciação entre instinto, pulsão, impulso e afeto, pois acreditamos que Nietzsche não se prende a termos específicos para falar das forças infraconscientes: todos são modalizações de forças. Esta posição se sustenta em uma referência apontada por Patric Wotling (1998), no seu texto "Der Weg zu den Grundproblemen": "Para designar as instâncias de origem infraconscientes, cuja atuação ele descobre no seio do pensar e do querer, Nietzsche utiliza os mais variados nomes 'instinto' (Instinkt), 'pulsão' (Trieb), 'afeto' (Affekt); ele não parece preocupado em se ater a uma terminologia fixa (...) Esta multiplicidade de denominações não era fortuita, mesmo em um período no qual ele estava alcançando o pleno domínio de sua nova psicologia, Nietzsche pareceu recusar obstinadamente a se ater a uma terminologia invariável e unívoca." (p. 12). Alinhados a Wotling, também optaremos pelo emprego do termo "infraconsciente". Mesmo não sendo um termo utilizado pelo próprio Nietzsche, mas sim cunhado pelo comentador (Wotling). Entendemos que uso dessa palavra realça uma concepção diferenciada existente entre as noções de inconsciente para Freud e para Nietzsche. Como a noção psicanalítica de inconsciente foi bastante difundida em toda cultura ocidental, torna-se uma batalha muito desgastante tentar mostrar a todo momento que a noção de inconsciente para Nietzsche é diferente daquela trabalhada por Freud. Assim, para evitar possibilidades de associação entre os termos, escolhemos também utilizar a palavra infraconsciente. A marca nietzscheana de inconsciente designa os eventos ou operações que ocorrem fora do âmbito da consciência. Mas, em Nietzsche, não podemos entender o inconsciente como um topos ou como uma estrutura, pois de forma alguma o filósofo concebe o inconsciente como uma unidade. Existem no homem forças inconscientes, mas não há um local específico onde elas atuam.

2 "A vontade de poder é a multiplicidade das forças em combate umas com as outras. Também da força no sentido de Nietzsche, só podemos falar em unidade no sentido de organização.” (Müller-Lauter, 1997, p. 74).

3 Nietzsche emprega o termo natureza segundo diferentes acepções. Para falar de natureza de um modo positivo, Nietzsche vai à Grécia antiga e resgata o termo physis. Somente concebendo o homem de acordo com a noção de physis é que o filósofo pode defender o "Tornar-se o que se é". Expressão que é tão importante para ele, especifica o subtítulo da sua autobiografia: Ecce Homo - Como tornar-se o que se é. Por certo, Nietzsche importa tal noção de Aristóteles que a explora e a conceitua em diversas de suas obras (no livro V da Metafísica, no livro II da Física, na Ética a Nicômaco e outras). Na Física, o filósofo grego defende que physis é o princípio interno de mudança que está presente em toda coisa viva e que explica sua capacidade de suportar mudança enquanto guarda a identidade de sua espécie. Assim Nietzsche, ao lado dos physiologos da Antiguidade pode falar de um "tornar-se o que se é" em meio a um mundo em completa mudança. Portanto, a noção natureza quando defendida por Nietzsche se distancia diametralmente daquela que ficou tão comum na Modernidade, que identifica natureza a uma essência estática. Um exemplo evidente do movimento crítico empreendido pelo filósofo alemão é o combate ao conceito de natureza defendido por Rousseau.

\section{Sobre o autor:}

Bruno Martins Machado: Psicólogo, Mestre e doutorando em Filosofia pela Universidade Estadual de Campinas (UNICAMP).

Endereço para correspondência: UNICAMP - Departamento de Filosofia - Instituto de Filosofia e Ciências Humanas - Caixa Postal 6110 - 13081-970 Campinas - SP - Endereço eletrônico: brmach@hotmail.com. 